\title{
Roll Back Malaria and the new partnership for Africa's development: Is there potential for synergistic collaboration in partnerships?
}

\author{
Edward Mberu Kamau
}

WHO/AFRO; Malaria Unit Box BE 773 Belvedere, Harare,Zimbabwe; Tel: +263-4-706951 Ext. 38054 / + 47241 38054;Fax: +263-4-746127 Email:kamaue@afro.who.int ;Alternativeemail:emberu@hotmail.com

\section{SUMMARY}

This synopsis seeks to highlight and promote the enormous potential that exists between these two initiatives that seek to address closely related issues and targeting the same populations at risk within a fairly well defined geographical setting. It also attempts to argue that malaria control, just like HIV-Aids control be given high priority in the New Partnership for Africa's Development (NEPAD) health agenda, as current statistics indicate that malaria is again on the rise. While much attention and billions of dollars have rightly been given to HIV-Aids research, treatment and prevention, malaria, and not Aids, is the region's leading cause of morbidity and mortality for children under the age of five years. This is the bad news. The good news is that unlike Aids, malaria treatment and prevention are relatively cheap. In addition, there is a payback to fighting malaria; support aimed directly at improving health, rather than poverty reduction, may be a more effective way of helping Africa to thrive. Robust and sustained growth may come to Africa through a mosquito net, Artemisinin-based Combination Therapies (ACTs) or a malaria vaccine, rather that a donor's cheque for economic development initiatives.

[Afr J Health Sci. 2006; 13:22-27]

\section{Introduction}

There have been substantial changes in malaria globally over the last decade. Among the changes has been drug resistance to commonly available antimalarials that spread to virtually all malaria endemic areas, and according to $\mathrm{WHO}$ /UNICEF [1] malaria report, there is evidence that as a consequent, mortality and morbidity increased in the 1990s. However, during the same period, the efficacies and costeffectiveness of several malaria control interventions have been demonstrated [2-8]. In response to the increasing malaria burden and the opportunities presented by new tools, the Roll Back Malaria (RBM) Partnership was launched in 1998, with the aim of reducing the malaria burden by at least $50 \%$ by the year 2010 through the application of evidence-based interventions and strengthening health delivery services. RBM is an international alliance of over 90 organizations including WHO, UNICEF and the World Bank, was meant to raise awareness on the existence of low-cost and effective interventions for malaria and the unfortunate low levels of spending on this tropical scourge. However, the existing RBM partnership should be broadened to include and be embedded within the African Union (AU) in order to fully exploit synergies inherent in the highest political organization in Africa. This will also position the AU in its rightful place with respect to advocacy support and mobilization of political will.

In 2000, 53 African Heads of State and Governments committed themselves to the Abuja Declaration calling for the scaling-up of the three core malaria control interventions and attain targets by 2005 . The African leaders were hoping to achieve the set goals (Abuja Targets) by using $\mathrm{RBM}$ as the main implementation instrument. Further to this, the Global Fund to 


\section{PERSPECTIVE}

Fight AIDS, Tuberculosis and Malaria (GFATM) was established in 2002, as a funding mechanism to give disease-endemic countries access to additional external resources for "The Big Three" diseases control. Currently, there are concerted efforts to promote and scale up three core malaria control interventions: insecticidetreated nets (ITNs), intermittent preventive treatment (IPT) during pregnancy and in infants, and prompt and effective treatment of clinical cases, with ACTs. During the $37^{\text {th }}$ Summit of the Organization of African Unity (OAU), the predecessor of AU, in July 2001, NEPAD was formally adopted. The NEPAD strategic orientation document arose from a mandate given to the five initiating Heads of State (Algeria, Egypt, Nigeria, Senegal and South Africa) by the OAU to develop an integrated socio-economic development framework for Africa.

NEPAD is not an implementation agency; its main role is to develop policies and to support member states to translate the policies into specific programmes. The core responsibility for implementation of NEPAD initiatives lies with the African countries, which will need to incorporate relevant strategies into their implementation plans. Health is a prominent NEPAD priority, recognising the social, economic and human impact of the huge burden of disease on the continent, in particular from AIDS, TB and malaria. NEPAD's malariaspecific policies, which overlap with those of RBM, include supporting the capacity for local production of essential drugs; advocating and negotiating support for the development of new drugs and vaccines needed for Africa, establishing regional reference laboratories to support research and scaling-up disease control interventions. The goal of the NEPAD health strategy is to substantially reduce the burden of disease, especially for the poorest populations in Africa, with its targets set on those of the United Nations Millennium Development Goals (MDGs), to halt and begin to reverse the spread of diseases by 2015 . The health strategy sets out to put Africa and its health systems and disease control interventions on target to meet the 2015 goal. It recognises the broader socio-economic and political factors that are at the root of much of the ill health on the continent and emphasises the contribution of other NEPAD programmes to addressing the broader issues that are undermining health. This is also in cognisance of the fact that economic development is crucial to peace and stability and NEPAD's strategy includes addressing poor governance, sociopolitical instability, economic underdevelopment, poverty, marginalization and displacement, lack of infrastructure, low educational levels, agricultural vulnerability and gender inequality, all of which affect health.

This health strategy adopts a holistic and integrated medium term approach that combines strengthening the health system needed to deliver services against the major burdens of disease, with emphasis on scaling up disease control programmes. The two are integral to one another, the system, and the deliverables, and need to be supported by renewed commitment and stewardship by governments. In addition, the health strategy recognises that health services and programmes against the major diseases are poorly funded to achieve the goals. It is therefore essential that African countries commit increased proportions of public expenditure to health, towards the target set by the African Heads of State in Abuja in 2000.

Malaria control and economic development are high on the public agenda of many developing countries, and more particularly in sub-Saharan Africa, where the two issues are intricately intertwined. Both are demanding in terms of human and financial resources, and seek to achieve the highest possible coverage. High population coverage of economic empowerment and malaria control initiatives among groups at risk will be necessary for the achievement of the Abuja declaration Targets, RBM strategy and MDGs.

\section{Rationale for Partnership}

The overlaps and similarities between RBM and NEPAD strategies make it imperative to forge a partnership, seek synergies and exploit vantage strengths by working together from the level of the village up to the headquarters of both organizations. Collaborative programmes could 
enhance the attainment of the impetus required to strengthen national health delivery and economic development systems. RBM should assume a coordinating role in establishing alliances and strengthening partnerships in health matters and take advantage of its presence at regional level and its closeness to national authorities to systematically and strategically engage other agencies on the continent, such as the Africa Union's Commission on Health.

\section{Malaria and economic development}

In Africa today, malaria is understood to be both a disease of poverty and a cause of poverty. It is estimated that malaria is responsible for a growth penalty of up to $1.3 \%$ per year in some African countries [9]. When compounded over the years, this penalty leads to substantial differences, totalling US\$12 billion annually, in GDP between countries with and without malaria and severely restrains the economic growth of the entire African Region [10]. It makes little sense to help with agricultural production, while leaving impoverished villages without improved roads, as they will need the infrastructure to transport their produce to the markets and to access health facilities. Additionally, limited improvements will be achieved if soils are fertile, but farming families continue to die of preventable and curable diseases such as malaria. Clearly, malaria is not only a major public health problem but also an important economic issue, calling for an integrated approach among effective and wider partnerships between government ministries, the African Union, NEPAD, Regional Economic Blocks, African Development Bank (ADB), the United Nations Economic Commission for Africa (UNECA), UNDP, civil society, the private sector and the local communities.

\section{Potential areas for collaboration}

To date, there has not been any formal or structured collaboration between NEPAD and RBM; however, there is adequate scope for exploring, developing and expanding crossprogramme synergies within the context of scaling up both the national malaria control interventions and development programmes.

\section{Communications and Advocacy}

Identification of best practices for use as strategic information for policy based on NEPAD's African Peer Review Mechanism (APRM), and monitoring implementation and evaluating impact of the Abuja and RBM targets and the MDGs which, at the current rate of progress in many African countries, will not reach the set targets. Partners to consolidate experiences and lessons learned on combined services and reciprocal benefits of effective collaboration.

\section{Resource mobilization, community involvement and education}

Despite attempts to integrate education and health sectors, the inclusion of malaria-related activities remains largely limited to projectspecific initiatives rather than any cocoordinated effort through partnership. The Highly Indebted Poor Country (HIPC) initiative of the World Bank is a reflection of renewed importance attached to ensuring the provision of adequate and sustainable health care. The importance of malaria is significantly highlighted in the HIPC process. HIPC was the first international response to provide debt relief to the world's poorest, most heavily indebted countries. Of the 26 countries that entered the HIPC programme, most are in Africa. These countries are saving an average of US\$ 1.3 billion per year compared with their debt payments in 1998. The resources freed from debt are used to support country-driven poverty reduction strategies. The Poverty Reduction Strategy Papers (PRSPs) are developed and implemented by national governments in close collaboration and consultation with NGOs.

Community involvement is a process whereby specific group(s) living in a geographically defined area and interacting with each other, actively identify their needs and make decisions to them [11]. Individual efforts in any infectious disease control effort are not sufficient to reduce or stop transmission, and community involvement is crucial and should go beyond compliance expectations. Due to community variability, there is need for cultural sensitivity in planning interventions and a 'community 
diagnosis' using a participatory approach should be carried out before interventions are planned. Further, it has been showed that the highest degree of community involvement is essential for dealing with interventions, which depend on behavioral changes, as it does with most diseases and poverty [12].

The enhanced integration of health into the education sector has the potential to accrue impacts beyond the immediate benefit to school children's education and health, such as the promotion of healthy practices in the broader community and the use of school buildings as centers for accessing antimalarial commodities. Several studies [13-15] and a technical report on the Partnership for Child Development [16] have demonstrated that malaria is an important public health problem for school children, indicating that schools have a role to play in helping to roll back malaria. The proposed 140 NEPAD's secondary e-Schools project in several 'first phase' African countries could be used to address malaria in school children by delivering simple messages about malaria prevention and treatment, as well as promotion of general primary healthcare activities, through skillsbased health education. The same channel could be used to promote schools as community focal points for re-treatment of insecticide treated materials; training of teachers to recognize malaria and the appropriate actions required treating it. This will require a thorough understanding of the evolving roles and collaboration, and policy dialogue between schools and health facilities, with technical and financial support from the ministries of health, education and finance. These education sector activities require an effective collaboration with the health sector to achieve full implementation.

It is the Ministry of Health and partners that retain overall responsibility for malaria control, and for the technical content of all advice and actions through schools. In addition to these efforts, it would be important to recognize and work with similar initiatives such as the WHO's e-health programme and AMREF's e-learning project. Of particular interest is a strategy that is able to promote a single, easily recognizable 'malaria treatment drug' that is readily available from multiple sources as this would greatly simplify the task of promoting prompt and effective treatment. A partnership between RBM and AU should expand the scope and further strengthen support for the school programme.

\section{Training and supervision}

Generally, intervention guidelines and methodologies developed by RBM will need to be adapted for use by NEPAD staff. In this era of scaling up interventions, NEPAD's human resource development and health units could provide valuable assistance with the design and implementation of malaria control training activities. Training packages for malaria control, specifically those intended for management at district level, should also include relevant NEPAD concepts and methodologies, and tools for micro planning for combined service delivery. As more countries move toward decentralized health systems, planning based on needs and coordinated sharing of human and financial resources by the major diseases control programmes, and strengthening of health services will become increasingly important.

\section{Possible Collaboration Strategies}

- Monitor the performance of member countries on malaria control activities as part of APRM, within agreed objectives, standard protocols, criteria and indicators. Currently, it is only HIV/AIDS that is part of this peer review mechanism. As shown recently [17-19] this can no longer be ignored given the emerging evidence of the complex interaction between maternal placental malaria and perinatal motherto-child HIV transmission. In addition, concerns have been raised regarding the interaction between antiretroviral drugs, prophylaxis with cotrimoxazole and antimalarial drugs during pregnancy and in vitro [20].

Elaborate a comprehensive national human resource development strategy to identify gaps, both in knowledge and coverage, harmonize training curriculum and clearly articulate the role of all stakeholders.

Design and promote the establishment of programme implementation and coordinating 
partnerships at country and community levels, for collaboration, shared service delivery, reduction of duplication and fragmentation and to ensure optimal utilization of resources.

- Develop and disseminate a single deliverable 'minimum package' for disease interventions and development initiatives.

- Support advocacy and communication for behaviour change efforts.

- Both NEPAD and RBM should inform and influence the strategic orientations of the proposed Commission for Africa (CfA) [http://www.commissionforafrica.org] and fully participate in the implementation and evaluation of CfA initiatives.

- Both NEPAD and RBM must use their special expertise vantage strengths (skills-mix) to mobilize political action and resources within the $\mathrm{AU}$ and the sub-regional institutions, including economic and trading blocks.

\section{Acknowledgement}

The views expressed by the author in this article do not reflect the views of his affiliated institutions. The author holds a MIM/TDR/RBM/AFRO Career Development Fellowship on Project Management of Tropical Diseases Research in Africa (Project ID A30082). The author is grateful to Dr Vincent U. Agu, External Relations Officer and Focal Point for NEPAD, Office of the Assistant Director-General, External Relations and Governing Bodies Cluster, WHO, Geneva, for comments on the manuscript.

\section{References}

1. WHO/UNICEF. The Africa malaria report. Geneva, World Health Organization, WHO/CDS/MAL/2003.1093).

2. Marsh VM, Mutemi WM, Willets A, Bayah K, Were S, Ross A and Marsh K. Improving malaria home treatment by training drug retailers in rural Kenya. Tropical Medicine and International Health. .2004; 9: 451-460.

3. Pagnoni FP, Convelbo N, Tiendrebeogo J, Cousens S, Eesposito F. A. Community-based programme to provide prompt and adequate treatment of presumptive malaria in children. Transactions of the Royal Society of Tropical Medicine and Hygiene. 1997; 91: 512-517.

4. Alonso PL, Lindsay SW, Armstrong JR, Conteh M, Hill AG, David PH, Fegan G, de Francisco A, Hall AJ and Shenton FC.The effect of insecticide treated bed nets on mortality of Gambian children. Lancet. 1991; 337: 1499-1502.

5. Nevill CG, Some ES, Mungala VO, Mutemi W, New L, Marsh K, Lengeler $\mathrm{C}$ and Snow RW. Insecticide treated bed nets reduce mortality and severe morbidity from malaria among children on the Kenyan Coast. Tropical Medicine and International Health. 1996; 2: 139146.

6. Binka FN, Mensah OA and Mills A. The cost-effectiveness of permethrin impregnated bed nets in preventing child mortality in Kassena-Nankana district of Northern Ghana. Health Policy. 1997; 41: 229-239.

7. Shulman CE, Dorman EK, Talisuna AO, Lowe BS, Nevill C, Snow RW, Jilo H, Peshu N, Bulmer JN, Graham S and Marsh K.,A community randomized controlled trial of insecticide-treated bed nets for the prevention of malaria and anaemia among primigravid women on the Kenyan coast. Tropical Medicine and International Health. 1998; 3: $197-$ 204.

8. Rogerson SJ, Chaluluka E, Kanjala M, Mkundilka $\mathrm{P}$, Mhano $\mathrm{C}$ and Molyneux ME. Intermittent sulfadoxinepyrimethamine in pregnancy: effectiveness against malaria morbidity in Blantyre, Malawi, in 1997-1999. Transactions of the Royal Society of Tropical Medicine and Hygiene. 2000; 94: 549-553.

9. Sachs J and Malaney P. The economic and social burden of malaria. Nature 2002; 415: 680-685.

10. "The Abuja Declaration on Roll Back Malaria in Africa". African Heads of 
State. Abuja, Nigeria. April $25^{\text {th }} 2000$. [http://www.rbm.who.int/docs/Abuja declaration. PDF].

11. Bermejo A and Bekui A. Community participation in disease control. Social Science \& Medicine 1993; 36:11451150.

12. Nichter M. Project community diagnosis: Participation research as a first step towards community involvement in primary health care. Social Science \& Medicine. 1984; 19: 237-252.

13. Colbourne MJ. The effect of malaria suppression in a group of Accra school children. Transactions of the Royal Society of Tropical Medicine and Hygiene. 1955; 49: 556-569.

14. Luxemburger C, Thwai KL, White NJ, Webster HK, Kyle DE, Maelankirri L, Chongsuphajaisiddhi T, Nosten F. The epidemiology of malaria in a Karen population on the western border of Thailand. Transactions of the Royal Society of Tropical Medicine and Hygiene. 1996; 90: 105-11.

15. Luxemburger C, Ricci F, Nosten F, Raimond D, Bathet S, White NJ. The epidemiology of severe malaria in an area of low transmission in Thailand. Transactions of the Royal Society of Tropical Medicine and Hygiene. 1997; 91: 256-62.

16. The Partnership for Child Development. Implications for school-based health programmes of age and gender patterns in the Tanzanian primary school. Tropical Medicine and International Health. 1998; 3: 850-853.

17. Ayisi JG, van Eijk AM, Newman RD, ter Kuile FO, Shi YP, Yang C, Kolczak MS, Otieno JA, Misore AO, Kager PA, Lal RB, Steketee RW and Nahlen BL. Maternal malaria and perinatal HIV transmission, Western Kenya. Emerging Infectious Diseases. 2004; 10: 643-52.

18. Brahmbhatt H, Kigozi G, WabwireMangen F, Serwadda D, Sewankambo N, Lutalo T, Wawer MJ, Abramowsky
C, Sullivan D and Gray R. The effects of placental malaria on mother-to-child HIV transmission in Rakai, Uganda. AIDS. 2003; 17:2539-41.

19. ter Kuile FO, Parise ME, Verhoeff FH, Udhayakumar V, Newman RD, van Eijk AM, Rogerson SJ and Steketee RW The burden of co-infection with human immunodeficiency virus type 1 and malaria in pregnant women in subSaharan Africa. American Journal Tropical Medicine Hygiene. 2004; 71: 41-54.

20. Skinner-Adams TS, McCarthy JS, Gardiner DL, Hilton PM and Andrews K. Antiretrovirals as antimalarial agents. Journal of Infectious Diseases. 2004; 190:1998-2000. 